\title{
Personal fear of death affects the proper process of breaking bad news
}

\author{
Aleksandra Ciałkowska-Rysz, Tomasz Dzierżanowski
}

Palliative Care Unit, Medical University of Lodz, Poland

Submitted: 4 January 2013

Accepted: 9 January 2013

Arch Med Sci 2013; 9, 1: 127-131

DOI: 10.5114/aoms.2013.33353

Copyright @ 2013 Termedia \& Banach

\section{Abstract}

Introduction: Breaking bad news may be affected not only by insufficient knowledge of a physician, but also by his attitude, religious beliefs, fears, lack of experience, etc. This survey was aimed to test the relation between physicians' fear of own death and philosophy of life and their inclination to break bad news.

Material and methods: One hundred seventy students of the last year of medical faculty filled in a 4-item questionnaire created by the authors. The participants were asked on their opinion on whether to inform patients on upcoming death, as well as fear of their own death and willingness to receive bad news. The last question was aimed to distinguish the respondents based on their determination in philosophy of life.

Results: Ninety-three percent of respondents think that patients should be informed about unfavorable prognosis but only $86 \%$ would like to be informed about their own upcoming death. There is a negative correlation between determination of philosophy of life and fear of own death $(p=0.024)$, but no correlation between fear of own death and the degree of religiousness (Fisher's accurate $p=0.18$ ). Persons determined to receive information on their own upcoming death are more prone to inform patients about their upcoming death $(\rho=0.31$; $p<0.0001$.

Conclusions: Personal fear of own death and low level of determination of philosophy of life may restrain medical professionals from breaking bad news to patients. Not only knowledge of the principles, but also personal attitude should be addressed in the curriculum of physician-patient communication education.

Key words: breaking bad news, fear of death, education.

\section{Introduction}

Patients suffering incurable diseases, especially in a terminal phase, have a right to be honestly informed about their state of health. According to the Polish Physician's Ethical Code, in case of an unfavorable prognosis, a physician ought to inform a patient about it with tact and caution [1]. Communicating bad news to patients well is not an optional skill but is an essential part of professional practice [2]. There is evidence that patients want to receive information regarding not only their diagnosis, but also their chances of cure, the side effects of therapy and a realistic estimate of how long they have to live, even more often than the doctors assume $[3,4]$.

A physician should know the essentials of physician-patient communication as well as principles of breaking bad news. These issues are an element of the palliative medicine curriculum. One of the aims of pallia-

\section{Corresponding author:}

Tomasz Dzierżanowski PhD

Palliative Care Unit Medical University of Lodz

2 Ciołkowskiego Str.

93-510 Lodz, Poland

Phone: +48 601334001

E-mail: tomasz.dzierzanowski @umed.lodz.pl 
tive medicine education is preparing a future physician to be ready to face up to the problems of a patient's suffering and death. During classes in palliative medicine, students learn inter alia how to talk to patients and break bad news concerning a diagnosis and prognosis. However, the amount of time dedicated to this educational element is insignificant. It is assumed that students should acquire the known principles of physician-patient communication in the early years of their studies, e.g. from lectures in clinical psychology.

The attitude of physicians with respect to breaking bad news may be affected not only by deficient knowledge, but also socio-cultural conditions, religious beliefs, cohesion of philosophy of life (conformity between one's conduct and convictions), or attitude towards one's own death. There is evidence that doctors inexperienced with breaking bad news are afflicted by a stress response more than experienced ones $[5,6]$. The bearer of bad news experiences strong emotions such as anxiety, a burden of responsibility for the news and fear of a negative response, which may result in a reluctance to deliver bad news [7]. This may make them refrain from informing patients properly. There is evidence that physicians are failing to inform patients about

Table I. The questionnaire of the survey

\begin{tabular}{|l|}
\hline $\begin{array}{l}\text { Q1. Should a patient be informed about unfavorable } \\
\text { prognosis and upcoming death? }\end{array}$ \\
\hline A. Definitely not \\
\hline B. Probably not \\
\hline C. Probably yes \\
\hline D. Definitely yes \\
\hline Q2. If you had only 2 weeks of life left to live, would you \\
like to know about it? \\
\hline A. Definitely not \\
\hline B. Probably not \\
\hline C. Probably yes \\
\hline D. Definitely yes \\
\hline Q3. Do you fear your own death? \\
\hline A. Definitely not \\
\hline B. No, not a lot \\
\hline C. Yes, a little \\
\hline D. Definitely yes \\
\hline Q4. Are you a religious person? \\
\hline A. No - these things do not interest me \\
\hline B. No - I do not believe in God (rational philosophy of life) \\
\hline C. Yes, quite religious (e.g. I believe in God and \\
sometimes take part in services) \\
\hline D. Definitely yes (I am deeply/internally religious - \\
I often pray and endeavor to live following the rules \\
of my religion) \\
\hline
\end{tabular}

an unfavorable diagnosis, although some patients with malignancy want to know if it is cancer, and some want to know as much as possible about their illness $[4,8,9]$.

Own fear of death may also impair the display of empathy on the physician's part, or other inadequate doctor's own reactions to death and dying [10]. Physician's fears may be displayed in physician's gestures and postures, which may influence the proper communication [11].

Information about the influence of the attitude and philosophy of life of doctors on the ability to break bad news is scarce and usually not considered in the guidelines and educational programs.

The influence of fear of own death and philosophy of life on the willingness to break bad news is a subject of this survey. To ensure a proper educational process of future physicians, we should learn the opinions of students on informing patients about upcoming death and possible causes of barriers to optimal communication. Making students aware of the influence of their own attitude towards death on the communication with a patient might increase the quality of formation of future physicians.

Therefore we aimed to test the inclination of students of the sixth (last) year of medical faculty to inform patients about unfavorable prognosis and upcoming death, as well as the relation between the inclination to inform patients about upcoming death and fear of own death and philosophy of life. This might help to indicate areas for improvement in the methods of teaching of physician-patient communication.

\section{Material and methods}

The questionnaire survey was performed in a group of students of the sixth (last) year of medical faculty at the Medical University of Lodz, Poland, commencing their palliative medicine course, before presenting the problems of communication of a physician with a patient and his/her family. The participation was voluntary and it was advised to omit the questions for which a participant did not want to answer.

The questionnaire consisted of 4 questions related to the survey (Table I). It was created by the authors - there were no similar questionnaires available in the literature.

\section{Statistical analysis}

For questions Q1, Q2 and Q3 a 4-point ordinal scale was used (definitely not -1 , probably not -2 , probably yes -3 , definitely yes -4 ).

In the descriptive analysis absolute frequency was used. The statistical dependence between nonparametric (ordinal numeric) measures was assess- 
ed using Spearman's rank correlation coefficient. Frequency analysis was performed using the $\chi^{2}$ test and Fisher's exact test. Value of $p$ less than 0.05 were considered statistically significant. Data were analyzed by Statistica 9.1 (StatSoft).

\section{Results}

One hundred and seventy students of age 24-28 filled in the questionnaire. All persons answered questions Q1, Q2 and Q3, and 4 persons abstained from reply to Q4 (“Are you a religious person?").

The majority (93\%) of participants think that a patient should be informed about unfavorable prognosis and upcoming death. Half of the respondents answered "definitely yes" (Figure 1).

For the question Q2, whether a respondent would like to know about their own upcoming death in the hypothetical situation where there are only 2 weeks of life left, $57 \%$ answered "definitely yes" and 29\% "probably yes". Fourteen percent of respondents would not wish to know about upcoming death (Figure 2).

Most of the responding students (56\%) are afraid of their own death. Fourteen percent definitely do not fear their own death (Figure 3). There is no correlation between fear of own death and the degree of religiousness (Fisher's accurate $p=0.18$ ). However, the persons determined in their philosophy of life (internally religious and determined irreligious) are less afraid of their own death than those who are less religiously committed (Fisher's accurate $p=0.024$ ).

A positive correlation was found between the answers to the question "Q1. Should a patient be informed about unfavorable prognosis and upcoming death?" and the answers to the question "Q2. If you had only 2 weeks of life left to live, would you like to know about it?" ( $\rho=0.31 ; p<0.0001)$. The more respondents are determined to receive information on their own upcoming death, the more they are inclined to inform patients about their upcoming death.

On the other hand, the more respondents were afraid of their own death, the less they would like to be informed about its approach ( $\rho=-0.17$; $p=0.031$ ).

\section{Discussion}

The surveyed group was homogeneous in age, as it consisted of the students of the sixth (last) year of the medical faculty, commencing the palliative medicine course. This group was selected in order to indicate areas for improvement and to assess the training needs in physician-patient communication for the future physicians.

Due to the sensitive nature of questions set in the questionnaire we limited questions that might disclose a participant. We decided not to include

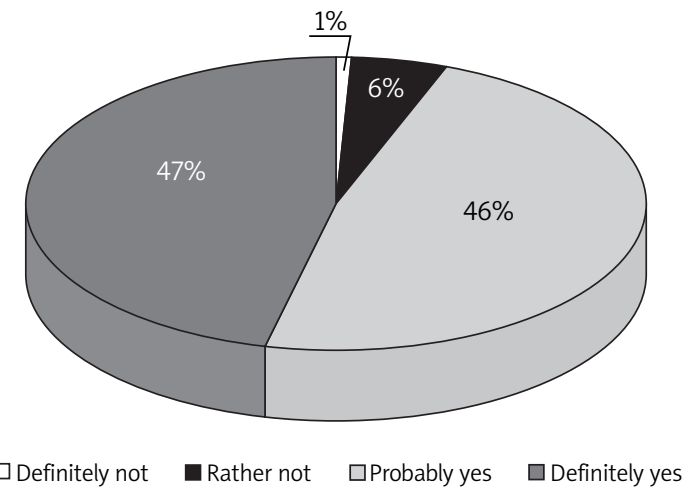

Figure 1. "Q1. Should a patient be informed about unfavorable prognosis and upcoming death?"

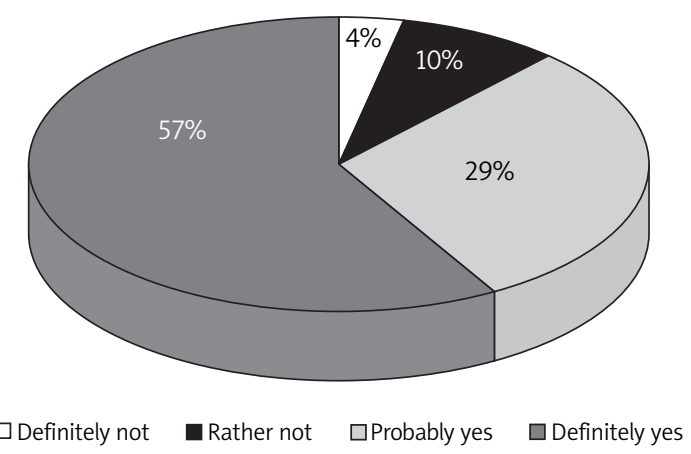

Figure 2. "Q2. If you had only 2 weeks of life left to live, would you like to know about it?"

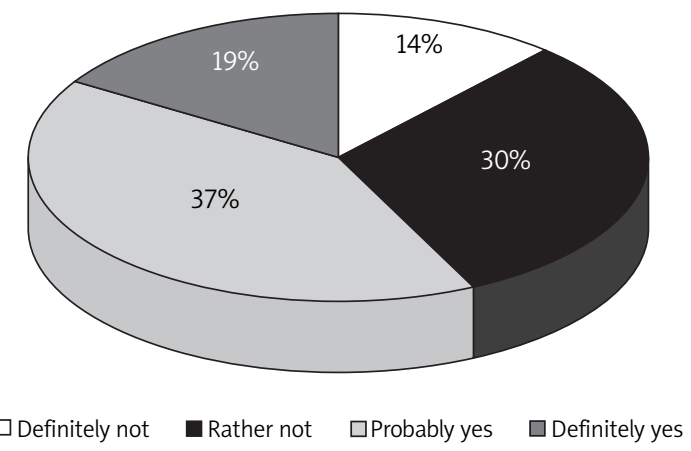

Figure 3. "Q3. Do you fear your own death?”

a question on age, as most of the students asked to take part in the survey were of the same age of 24-26 years and only a few of them were $27-28$. No question on gender was included either. No analysis of age or gender was planned, and including these two questions might decrease the reliability of the survey.

However, taking into consideration the overall number of students, almost all of them filled in the questionnaire. Except question Q4, all participants responded. Four persons did not answer question Q4: "Are you a religious person?" It may be as- 
sumed that the conditions for free and comfortable answering of sensitive questions were guaranteed.

The majority of students commencing their course in palliative medicine would inform a patient about an unfavorable prognosis in a hypothetical situation. In spite of that, only half of them were convinced about breaking bad news and $7 \%$ of responders thought that patients should not be informed about upcoming death. It should be ensured that there is a sufficient amount of time and attention in the curriculum on the importance of breaking bad news for the optimal palliative care process.

However, in another survey on physicians and students after the course in palliative medicine, according to $30-38 \%$ of respondents patients should not be informed about an unfavorable prognosis [12].

In the hypothetical situation of one's own upcoming death, $14 \%$ of respondents would not like to know about it, but many more of the participants of the survey would decide to learn of an unfavorable prognosis. Significantly more students (93\%) think that a patient should be informed about bad news, in comparison to the number of respondents who would like to be informed if they were in a situation of upcoming death (86\%). Inconsistency was found between the attitude of breaking bad news to others and the attitude of readiness to receive such bad information. However, it should be borne in mind that it refers to a hypothetical situation only, and the real behavior could differ from the declared one. This question was aimed to test to what degree fear of own death impairs a physician's tendency to break bad news to a patient. The correlation between these two attitudes was found to be statistically significant. So it needs to be taken into consideration, when planning the curriculum in palliative medicine, not only to set an appropriate scope of information, but also to address the issue of the influence of one's own attitude on the behavior towards a patient.

The preference to limit getting bad news may result from the fear of one's own death. However, the distribution of responses is inconsistent in these two aspects tested. Over half of the respondents are afraid of their own death, but only several percent do not wish to be informed about an unfavorable prognosis. So there is quite a big group of people who fear their own death and in spite of that would like to know the truth about upcoming death. It was also found that the more the persons fear their own death, the less they want to know about its approach, although the correlation is weak $(\rho=-0.17 ; p=0.031)$.

It was not found that the degree of religiousness impacts the attitude of fear of own death. However, the persons determined in their philosophy of life (internally religious and determined irreligious) are less afraid of their own death than those who are less religiously committed. So maybe it should be considered in the process of education of the future physicians who will take care of patients with incurable diseases and the dying to point out that not the philosophy of life itself, but its determination (coherence of philosophy of life and attitude) impacts perception of matters of life and death, and projection of own values and fears to patients. And this may be a barrier to optimal communication.

Physicians need to accept that patients expect high levels of both empathy and information quality, no matter how bad the news is [13]. Kübler-Ross pointed out that patients usually know the bad news about upcoming death, regardless of whether they are informed by the physician. She also underlined that only those patients who face up to their dying are able to pass away calmly [14]. This makes breaking bad news crucial for the effective palliative care process. It is more worthwhile to inform patients about their upcoming death than not to inform them.

Poor communication performance in breaking bad news is also a result of burnout and fatigue [5]. These factors are the result of current and prolonged overburden of work and exposure to other's suffering. They may be managed or even prevented when early corrective activities are implemented. On the other hand, according to KüblerRoss, the physician should not force his own beliefs of what is good and bad for the patient. She advises not to project one's attitude onto others [14]. Unlike burnout and fatigue, a personal value system is not a subject to prevent and is a basis for individual attitude. As such, it cannot be easily modified. However, a physician should be aware of its impact and one's own limitations related to it. In this study we demonstrated that personal philosophy of life and fear of own death negatively impact the decision on breaking bad news. This fact should be taken into consideration in the educational process of future medical professionals. It is important not only to teach them the rules of high quality physician-patient communication, but first of all to get them to understand their own limitations that influence it.

It is an open issue whom to provide appropriate training on breaking bad news. Should it be students of a medical faculty or consultants who undergo such a training module? There are deficiencies observed in different countries. In one survey performed in the UK half of experienced consultants had received no formal training in this area and the vast majority regarded such training as useful [15]. These deficiencies seem to differ in specialization groups. In one survey it was found that the gaps are deeper in surgeons than non-surgical specialists or general practitioners [16]. Further con- 
sideration on the timing of the educational program on communication with a patient is required then.

This survey has several limitations, though in our opinion, the conclusions seem to be reliable and valid. We decided not to set a question on age, as nearly all the respondents were of known age of 24-26 years and only a few of them were 27-28. This information would not add value, but might decrease the truthfulness of the respondents, as the questionnaire included sensitive questions. Likewise, there was no analysis according to gender planned, as collecting such data might significantly decrease the reliability of the answers to sensitive questions too. On the other hand, the authors did not plan to diversify the possible recommendations resulting from the conclusions in respect of gender. In our opinion the recommendations should be universal, as the curriculum of the medical faculty is. The question Q2 applied to a hypothetical situation, not to a real one that a respondent was in. It is possible that the responses would differ significantly if a real threat of upcoming death arose, either one's own or a patient's one, as underlined above. In our opinion, own experience modifies physicians' behavior in the area of communication with patients to the highest degree. In spite of that, it remains true that the less determined the philosophy of life is, the greater is the fear of one's own death (declared directly or manifested by greater reluctance to learn of an unfavorable prognosis). It results in a decreased tendency to break bad news to patients. Thus awareness of one's own fears and their influence on communication with a patient is crucial. We hope these findings may be useful for the national as well as European initiatives to change and harmonize fundamental aspects of all higher education in the area of palliative medicine [17].

In conclusion, personal fear of death may restrain inexperienced medical professionals from breaking bad news to patients. The level of determination of philosophy of life, but not religious belief itself, impacts the tendency to inform patients about upcoming death. Personal attitude should be addressed within the curriculum of physician-patient communication education.

\section{References}

1. Physician's Ethical Code. Chief Physicians Chamber in Poland. http://www.nil.org.pl/dokumenty/kodeks-etykilekarskiej [Polish].

2. Breaking Bad News Regional Guidelines, National Council for Hospice and Specialist Palliative Care Services (2003) http://www.dhsspsni.gov.uk/breaking_bad_news.pdf

3. Sutherland HJ, Llewellyn-Thomas HA, Lockwood GA, Tritchler DL, Till JE. Cancer patients: their desire for information and participation in treatment decisions. J R Soc Med 1989; 82: 260-3.
4. Meredith C, Symonds P, Webster L, et al. Information needs of cancer patients in West Scotland: cross sectional survey of patients views. BMJ 1996; 313: 724-6.

5. Ptacek JT, Eberhardt TL. Breaking bad news. A review of literature. JAMA 1996; 276: 496-502.

6. Brown R, Dunn S, Byrnes K, Morris R, Heinrich P, Shaw J. Doctors' stress responses and poor communication performance in simulated bad-news consultations. Acad Med 2009; 84: 1595-602.

7. Tesser A, Rosen S, Tesser M. On the reluctance to communicate undesirable messages (the MUM effect) a field study. Psychol Rep 1971; 29: 651-4.

8. Goldberg R, Guadagnoli E, Silliman R, et al. Cancer patients' concerns: congruence between patients and primary care physicians. J Cancer Educ 1990; 5: 193-9.

9. Meredith C, Symonds P, Webster L, et al. Information needs of cancer patients in West Scotland: cross sectional survey of patients views. BMJ 1996; 313: 724-6.

10. Fields SA, Johnson WM. Physician-patient communication: breaking bad news. W V Med J 2012; 108: 32-5.

11. Bruera E, Palmer JL, Pace E, et al. A randomized, controlled trial of physician postures when breaking bad news to cancer patients. Palliat Med 2007; 21: 501-5.

12. Leppert W, Łuczak J, Góralski P. Selected problems of palliative care and euthanasia in physicians and medical students views. Polska Medycyna Paliatywna 2005; 4: 67-76.

13. Munoz Sastre MT, Sorum PC, Mullet E. Breaking bad news: the patient's viewpoint. Health Commun 2011; 26: 649-55.

14. Kübler-Ross E. On death and dying. Routledge 1969.

15. Barnett MM, Fisher JD, Cooke H, James PR, Dale J. Breaking bad news: consultants' experience, previous education and views on educational format and timing. Med Educ 2007; 41: 947-56.

16. Barnett MM. Effect of breaking bad news on patients' perceptions of doctors. J R Soc Med 2002; 95: 343-7.

17. Schaller B. Medical education and the Bologna process. Arch Med Sci 2007; 3: 3-4. 